\title{
Assessing the Organizational Culture of Thai Synchrotron Light Research Institute
}

\section{Sarawut Sujitjorn1, Nuttapol Assarut', Naphatthira Mungthanaworakun1, Porama Tiptanasup ${ }^{3}$, Nuttawutti Tavornvisitporn ${ }^{3}$}

\author{
${ }^{1}$ Synchrotron Light Research Institute (Publ. Org.), Nakhon Ratchasima, Thailand \\ ${ }^{2}$ Chulalongkorn Business School, Chulalongkorn University, Bangkok, Thailand \\ ${ }^{3}$ Baramizi Lab Co. Ltd., Bangkok, Thailand \\ Email: sarawut.sujitjorn@slri.or.th,nuttapol@cbs.chula.ac.th,naphatthira@slri.or.th
}

How to cite this paper: Sujitjorn, S., Assarut, N., Mungthanaworakun, N., Tiptanasup, P. and Tavornvisitporn, N. (2020) Assessing the Organizational Culture of Thai Synchrotron Light Research Institute. Open Journal of Business and Management, 8, 649-659.

https://doi.org/10.4236/ojbm.2020.82039

Received: January 20, 2020

Accepted: March 7, 2020

Published: March 10, 2020

Copyright (c) 2020 by author(s) and Scientific Research Publishing Inc. This work is licensed under the Creative Commons Attribution International License (CC BY 4.0).

http://creativecommons.org/licenses/by/4.0/

\begin{abstract}
Organizational culture of an advanced physics institute in Thailand has been studied. The purpose of this work is to find out the existing dominant cultures of the institute. The authors applied qualitative and quantitative research approaches, i.e. focused group interview and questionnaire survey, respectively, and present their findings herein. For Synchrotron Light Research Institute (SLRI) explored, their dominant cultures are characterized by strategic direction, capability development, and organizational learning. These are considered as the top three strengths of the institute. The second-to-top strengths are team orientation, customer focus, and competition mind. The two sets of strengths solidly support the following dominant cultures: mission or competence, changeability or cultivation, and collaboration or involvement. These norms form SLRI's core organizational cultures suitable for being a service and innovative organization. Since the institute is a non-profit enterprise owned by the Thai Government, safety and control culture must be practiced, however to a lesser extent.
\end{abstract}

\section{Keywords}

Organizational Culture, Non-Profit Organization, Dominant Culture, Strength

\section{Introduction}

Synchrotron Light Research Institute (SLRI), Thailand, has been established by the Thai Government since 2008 as a public organization. Its functions cover synchrotron light and professional services, and training of young scientists and engineers working in the field. The first decade has recently passed. It is inter- 
esting and will be useful to know the culture of this young organization. Cultural fit of an organization to its structure and strategy is important to ensure success. Regarding this, $\mathrm{CEO}$ and the management team must pay attention to the organizational culture, maintain and strengthen the appropriate one, and suppress or reduce the unfit culture. The report on organizational culture studies of SLRI is hence the subject of this article.

SLRI is an advanced physics institute aimed to serve researchers in academia and industry by providing synchrotron radiation, research, and professional services. The organization's structure consists of three major pillars: 1) light source and beamline facilities (synchrotron radiation laboratories and end stations), 2) engineering supports, and 3) strategic and administrative supports. At present, it has 201 staff members. Among those, 50 are doctoral degree holders in science and engineering, 58 are supportive staff members of strategic and administrative pillars, and the rest of 93 are engineers, scientists, and technicians. Readers can find more details of SLRI's organizational structure on our website (www.slri.or.th).

To study the organizational culture of SLRI, we conducted a quantitative research to gain a broad picture of our existing cultures. Further actions should be made in order to either reinforce or reduce the relevant cultures accordingly. Our study is enhanced by qualitative research, in which we conducted a focused group interview of executives and managers hereinafter referred to as the management team (MT). The results reveal the cultural characteristics that the MT had tried to hardwire into their teams. The MT must decisively apply them to achieve a positive outcome for the organization. These issues are discussed promptly in this article.

\section{Literature Review}

Competitive sustainability of an organization can be successfully achieved through its workforces with strong organizational culture, which requires a long-term commitment of its leader to build. Unfortunately, culture can be easily damaged or destroyed if the leader lacks understanding, and let unfit behavior go on in an uncontrolled manner.

Culture and engagement are two different things. Engagement score is not a representation or proxy of a culture index. Engagement is related to a happy workplace. Culture is the behavioral patterns of workers. In a workplace, those behaviors are encouraged, discouraged or tolerated. There is no one-size-fits-all culture for an organization, i.e. your organizational culture depends on your business imperative.

For our first decade (during 2009-2018), SLRI had completed the construction of full 12 synchrotron beamlines, i.e. research experimental stations utilizing synchrotron radiation. The institute successfully provided synchrotron radiation services to industry and academia. Its successes were well proven by an accumulated economic value added (EVA) achieved of about 320 million USDs. The institute also won many national and international awards for performance 
achievements, and management systems. Our vision for the next second decade is to be a world-class organization for services and innovations. It is therefore very challenging for the MT to glide their teams towards strategic goals. Importantly should the MT realize, organizational culture is one of the 4 core organizational components that are core people, core structures, core cultures, and core processes [1]. Core cultures or dominant cultures strategically guide desirable behaviors that should be aligned with core (work) processes, and in turn with core structures support core people to perform productively. Enterprise's leader should manage well to avoid conflict or misalignment among the core organizational components, otherwise damaging internal resistance would be resulted.

Till now there has been no clear agreement on the definition of organizational culture. "The way we do things around here" seems to gain a common acceptance from communities [2]. On the cultural web, Professor Gerry Johnson refers to organizational culture as "the taken-for-granted assumptions and behaviors that make sense of people's organizational context and therefore contributes to how groups of people respond and behave in relation to issues they face" [3] [4].

Denison [5] classified organizational culture into 4 groups, i.e. adaptability, consistency, involvement, and mission. Similarly to Denison, Schneider [6] proposed 4 groups of culture with different jargons: competence, collaboration, cultivation, and control (or 4 C's). Quinn \& Cameron [7] classified 4 cultural types, i.e. adhocracy (or create), clan (or collaborate), hierarchy (or control), and market (or compete). Recently, Groysberg et al. [8] identified 8 cultural styles being mapped onto 4 quadrants of 2 axes namely flexibility vs stability, and interdependence vs independence axes, respectively. These 8 styles include enjoyment, learning, purpose, caring, order, safety, authority, and result. Noticeably, the styles nicely agree with the culture classifications similarly proposed by Denison [5], Schneider [6], and Quinn \& Cameron [7]. As Ulrich said in his book [9], "investors want organizations with effective cultures". Leaders are responsible for creating effective cultures, while they play a key role in helping organizations deliver strategic goals. Therefore, assessing culture is an important milestone to organization success.

\section{Methods}

For our qualitative and quantitative research approaches, we applied the above concepts, and propose 17 cultural characteristics that can be arranged into 4 groups as follows:

Group I: Collaboration or Involvement consists of empowerment, team orientation, capability development, caring, and enjoyment;

Group II: Consistency or Control/Hierarchy consists of core values (order), agreement (humble), coordination and integration (order and integrity), and authority;

Group III: Adaptability or Changeability/Cultivation consists of creating 
change, customer focus, organizational learning, and entrepreneurial;

Group IV: Mission or Competence consists of strategic direction and intent, goals and objectives, vision, and result-oriented (competition mind).

These characteristics were used as a set of culture card research tool for our qualitative and quantitative researches.

\subsection{Qualitative Research}

We interviewed our 12 MT-members. The interviewees included CEO, deputy directors, assistant directors, and chiefs of divisions. The interviewing questions are 1) the importance of organizational culture, 2) current dominant cultures, 3) cultures to be enhanced or subdued, and 4) ideal cultures for the next decade. Their viewpoints are summarized, analyzed, and discussed in the following sections.

\subsection{Quantitative Research}

We conducted a survey of our 201 employees via a set of questionnaire consisting of 55 questions for the 17 cultural characteristics. Those questions were arranged into the culture card style. The employees expressed their viewpoints on the Liberty scale ( 1 to 5 as strongly disagree to strongly agree). We used Cronbach's alpha reliability coefficients to identify the reliability of our tool. We also compared the average variance extracted (AVE) with the correlation coefficients to verify validity of the tool. We applied principle component, and cluster analyses to the results to find out our current and existing cultures. Analysis of the results and discussions appear in the following sections.

\section{Results}

\subsection{Qualitative Research Results}

The followings are viewpoints of the MT members.

1) The importance of organizational culture. The majority of the members realized the vitality of organizational culture to organizational successes, and confirmed that they knew how to create it. They were also aware of the connection between culture and corporate performance.

2) Current cultures. The team agreed upon the following existing dominant cultures: collaboration, determination and commitment (results oriented), and service mind.

3) Cultures to be enhanced or subdued. Three cultures to be enhanced include caring and team, organizational results oriented, and open-minded. Additionally, safety culture cannot be overlooked. Cultures to be subdued are personal-oriented behavior, and dodging of jobs.

4) Ideal cultures for the next decade. Based on weighted averages of the viewpoints' scores, the 3 ideal cultures for the next decade of SLRI include team oriented as top, strategic intent and goal-oriented, learning and change as second, and customer focus as third. 


\subsection{Quantitative Research Results}

The institute promoted the survey by communicating among employees about its importance and benefits to their workplace. The survey team set up a room having several laptops with wifi connections for employees to sit in and answer the questionnaire. Employees were grouped and invited to take part in. The activity took 21 days, and results were analyzed.

There were 141 responders or $70.15 \%$ of the total number of employees. Among them, about $18 \%$ are executives and line managers; the rest are operators and supportive staff members. About $22 \%$ of the 141 are doctoral degree holders; $27 \%$ hold master degrees; $37 \%$ hold bachelor degrees, and the rest hold vocational school certificates. Regarding job functions, $29.08 \%$ are back-office supportive staff; $32.62 \%$ are scientists and researchers; $34.04 \%$ are engineers and technicians, and the rest of $4.26 \%$ did not declare their job functions. Majority of our employees are 30 - 45 years of age, while their average age is about 39 years old.

We applied confirmatory factor analysis by using the SmartPLS software package to confirm the reliability of our research tool. As a result, Table 1 declares the

Table 1. Average variance extracted (AVE), Composite Reliability, Cronbach's Alpha, and Communality.

\begin{tabular}{|c|c|c|c|c|}
\hline Cultural Characteristic & AVE & $\begin{array}{l}\text { Composite } \\
\text { Reliability }\end{array}$ & $\begin{array}{c}\text { Cronbach's } \\
\text { Alpha }\end{array}$ & Communality \\
\hline X01_Empowerment & 0.677 & 0.862 & 0.756 & 0.677 \\
\hline X02_Team_Orientation & 0.703 & 0.876 & 0.789 & 0.703 \\
\hline X03_Capability_Development & 0.745 & 0.897 & 0.828 & 0.745 \\
\hline X04_Caring & 0.717 & 0.910 & 0.868 & 0.717 \\
\hline X05_Core_Values & 0.810 & 0.927 & 0.882 & 0.810 \\
\hline X06_Agreement & 0.869 & 0.930 & 0.849 & 0.869 \\
\hline X07_Coordination & 0.755 & 0.902 & 0.838 & 0.755 \\
\hline X08_Authority & 0.780 & 0.914 & 0.859 & 0.780 \\
\hline X09_Creating.Change & 0.808 & 0.927 & 0.881 & 0.808 \\
\hline X10_Customer.Focus & 0.892 & 0.943 & 0.879 & 0.892 \\
\hline X11_Organizational_Learning & 0.646 & 0.844 & 0.723 & 0.646 \\
\hline X12_Entrepreneurial & 0.742 & 0.920 & 0.884 & 0.742 \\
\hline X13_Strategic_Direction & 0.831 & 0.937 & 0.899 & 0.831 \\
\hline X14_Goal_Objectives & 0.806 & 0.926 & 0.880 & 0.806 \\
\hline X15_Vision & 0.827 & 0.935 & 0.895 & 0.827 \\
\hline X16_Competition_Mind & 0.792 & 0.939 & 0.913 & 0.792 \\
\hline X17_Enjoyment & 0.769 & 0.909 & 0.849 & 0.769 \\
\hline
\end{tabular}


following values: average variance extracted (AVE), composite reliability, Cronbach's alpha, and communality, respectively. The tool is acceptable if each characteristic has its AVE greater than 0.6, composite reliability greater than 0.7 , Cronbach's alpha greater than 0.7 , and communality greater than 0.4 . The details in Table 1 confirm that all these requirements are met. For measurement of discriminant validity of the method and tool, Table 2 gives details of the squared-roots of AVE values, and the correlation coefficients of 17 characteristics. The diagonal components are the squared-root values, while all the rest of the figures are correlation coefficients. Note that the squared-root of AVE in each column is the greatest number in the column. It means that our method and tool possess discriminant validity.

Scores from our staff members answering the questionnaire were observed that about $7 \%$ of the data contained some biases. Some responders gave flat scores of 5 or 3 to all questions. So, these data were cut off, and weighted averages of the rest of the data were calculated. Table 3 summarizes those values against each characteristic grouped into 4 cultural norms. They are also plotted as a radar chart shown in Figure 1.

Table 2. The results of the discriminant validity assessment.

\begin{tabular}{|c|c|c|c|c|c|c|c|c|c|c|c|c|c|c|c|c|c|}
\hline Cultural Characteristic & $\mathrm{X} 01$ & X02 & $\mathrm{X} 03$ & X04 & X05 & X06 & X07 & X08 & X09 & $\mathrm{X} 10$ & $\mathrm{X} 11$ & $\mathrm{X} 12$ & $\mathrm{X} 13$ & $\mathrm{X} 14$ & $\mathrm{X} 15$ & $\mathrm{X} 16$ & $\mathrm{X} 17$ \\
\hline X01_Empowerment & $\underline{0.823}$ & & & & & & & & & & & & & & & & \\
\hline X02_Team_Orientation & 0.765 & $\underline{0.838}$ & & & & & & & & & & & & & & & \\
\hline $\begin{array}{c}\text { X03_Capability_Develop } \\
\text { ment }\end{array}$ & 0.707 & 0.735 & $\underline{0.863}$ & & & & & & & & & & & & & & \\
\hline X04_Caring & 0.758 & 0.759 & 0.739 & $\underline{0.847}$ & & & & & & & & & & & & & \\
\hline X05_Core_Values & 0.774 & 0.748 & 0.808 & 0.831 & $\underline{0.900}$ & & & & & & & & & & & & \\
\hline X06_Agreement & 0.678 & 0.674 & 0.666 & 0.742 & 0.806 & $\underline{0.932}$ & & & & & & & & & & & \\
\hline X07_Coordination & 0.752 & 0.699 & 0.701 & 0.763 & 0.827 & 0.798 & $\underline{0.869}$ & & & & & & & & & & \\
\hline X08_Authority & 0.730 & 0.707 & 0.726 & 0.753 & 0.843 & 0.717 & 0.740 & $\underline{0.883}$ & & & & & & & & & \\
\hline X09_Creating.Change & 0.738 & 0.691 & 0.752 & 0.688 & 0.779 & 0.709 & 0.772 & 0.739 & $\underline{0.899}$ & & & & & & & & \\
\hline X10_Customer.Focus & 0.626 & 0.552 & 0.633 & 0.633 & 0.714 & 0.543 & 0.648 & 0.606 & 0.676 & $\underline{0.945}$ & & & & & & & \\
\hline $\begin{array}{c}\text { X11_Organizational_ } \\
\text { Learning }\end{array}$ & 0.702 & 0.662 & 0.723 & 0.723 & 0.766 & 0.675 & 0.718 & 0.717 & 0.717 & 0.575 & $\underline{0.803}$ & & & & & & \\
\hline X12_Entrepreneurial & 0.716 & 0.699 & 0.671 & 0.671 & 0.797 & 0.677 & 0.733 & 0.810 & 0.810 & 0.762 & 0.741 & $\underline{0.861}$ & & & & & \\
\hline X13_Strategic_Direction & 0.640 & 0.682 & 0.544 & 0.544 & 0.665 & 0.587 & 0.574 & 0.630 & 0.630 & 0.499 & 0.623 & 0.760 & $\underline{0.912}$ & & & & \\
\hline X14_Goal_Objectives & 0.739 & 0.697 & 0.668 & 0.692 & 0.782 & 0.705 & 0.724 & 0.745 & 0.745 & 0.567 & 0.717 & 0.815 & 0.757 & $\underline{0.898}$ & & & \\
\hline $\mathrm{X} 15$ _Vision & 0.746 & 0.678 & 0.731 & 0.698 & 0.820 & 0.719 & 0.734 & 0.813 & 0.813 & 0.643 & 0.704 & 0.823 & 0.745 & 0.849 & $\underline{0.909}$ & & \\
\hline X16_Competition_Mind & 0.705 & 0.675 & 0.712 & 0.719 & 0.794 & 0.662 & 0.720 & 0.779 & 0.779 & 0.664 & 0.726 & 0.816 & 0.689 & 0.779 & 0.820 & $\underline{0.890}$ & \\
\hline X17_Enjoyment & 0.621 & 0.675 & 0.588 & 0.693 & 0.690 & 0.620 & 0.693 & 0.634 & 0.634 & 0.539 & 0.702 & 0.656 & 0.561 & 0.623 & 0.613 & 0.603 & 0.877 \\
\hline
\end{tabular}


Table 3. The results of cultural characteristics and cultures.

\begin{tabular}{|c|c|c|}
\hline Culture & Cultural Characteristic & WA \\
\hline \multirow[t]{5}{*}{ Involvement (Collaboration) } & X01_Empowerment & 3.670 \\
\hline & X02_Team_Orientation & 3.743 \\
\hline & X03_Capability_Development & 3.805 \\
\hline & X04_Caring & 3.238 \\
\hline & X17_Enjoyment & 3.132 \\
\hline \multirow[t]{4}{*}{ Control (Hierarchy) } & X05_Core_Values & 3.410 \\
\hline & X06_Agreement & 3.396 \\
\hline & X07_Coordination & 3.198 \\
\hline & X08_Authority & 3.417 \\
\hline \multirow[t]{4}{*}{ Changeability (Cultivation) } & X09_Creating.Change & 3.622 \\
\hline & X10_Customer.Focus & 3.684 \\
\hline & X11_Organizational_Learning & 3.730 \\
\hline & X12_Entrepreneurial & 3.454 \\
\hline \multirow[t]{4}{*}{ Competence (Mission) } & X13_Strategic_Direction & 4.002 \\
\hline & X14_Goal_Objectives & 3.394 \\
\hline & X15_Vision & 3.427 \\
\hline & X16_Competition_Mind & 3.493 \\
\hline
\end{tabular}

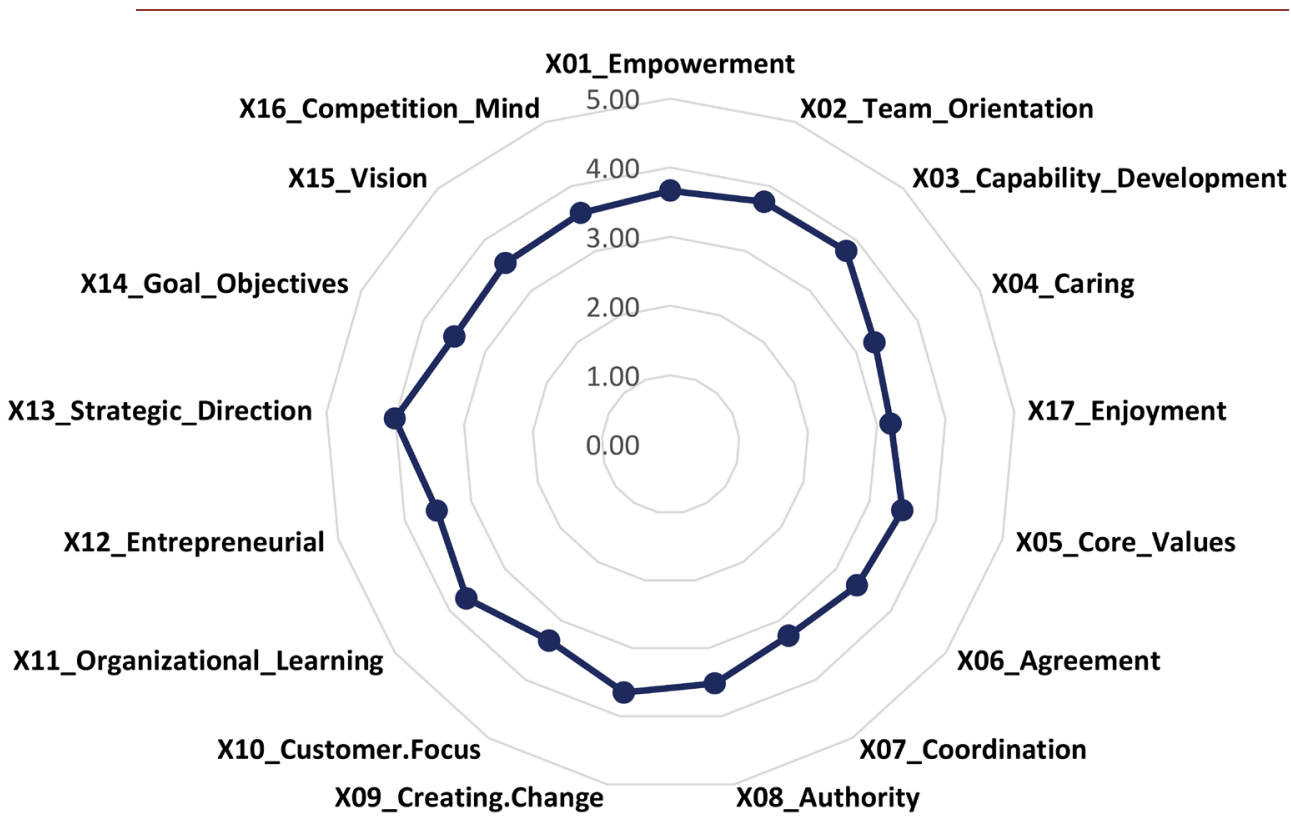

Figure 1. Plot of cultural characteristic scores.

\section{Discussions and Findings}

The viewpoints of the MT members though inhomogeneous show a similar direction of SLRI that is an advanced scientific services and innovative organization. The MT wants to see the institute successfully innovate. To achieve this, 
team or collaboration culture is a solid ground for driving the success. The existing and current dominant cultures are collaboration, commitment to results, and service mind. These would make employees become engaged in their jobs and the organization.

Referring to Figure 1, the "strategic direction" stands out. The message conveyed is that SLRI has a very clear strategic direction. Considering the data sets in Table 3, the strategic direction belongs to the "competence" cultural norm. Within this norm, the scores of "competition mind" and "vision" come second and third, respectively. These figures radiate the message that our employees feel that our strategic direction and vision are so clear, and they are willing to pursuit their success in a competitive mode. When we consider the 4 sets of data according to the cultural norms, we can observe that the set belonging to the "control" norm possesses weighted averages lower than the other sets. It gives a clue that the control culture is not appropriate for an innovative organization in comparison with the rest three norms. Since SLRI is a non-profit organization owned by the Government of Thailand, owing to this status, we cannot drop out the control culture. Direct and command still have their roles in organizational management to a lesser extent. For instance, we have to conduct internal audit, enterprise risk management, health and safety measures, etc. The cultural norms most suitable for SLRI are collaboration or involvement, cultivation or changeability, and competence or mission. We also determined mean values of the weighted averages for the cultural norms. The following means are obtained: 3.623 for cultivation (or changeability), 3.579 for competence (or mission), 3.528 for collaboration (or involvement), and 3.355 for control (or hierarchy). The effective or root-mean-squared values of those weighted averages are also calculated. They are 3.624, 3.579, 3.528, and 3.356, respectively. Differences among the means and effective values pairs are insignificant. This means that fluctuation in data has little effect. At this stage, we can conclude that our existing and current dominant cultures are competence, cultivation, and collaboration. These strongly support our desire to be an excellent service and innovative organization.

Considering each data set belonging to each cultural norm in Table 3, we can see that each set contains the maximum and the second to maximum values. The 3 maxima stress our dominant cultures, i.e. strategic direction, capability development, and organizational learning. These are top 3 strengths characterizing our dominant cultures. The seconds to maxima also stress the same dominant cultures, i.e. team orientation, customer focus, and competition mind (results oriented). These are plotted as shown in Figure 2 having solid and dashed lines representing the conjoined top 3 strengths, and the second-to-top. SLRI's executives and managers should pay attention a little bit more on strengthening customer focus and team orientation characteristics among their staff members. This would render even better performance and outstanding outcomes of the organization. According to the figures in Table 3, authority, core values and agreement characteristics are significant components of our control culture. Our 


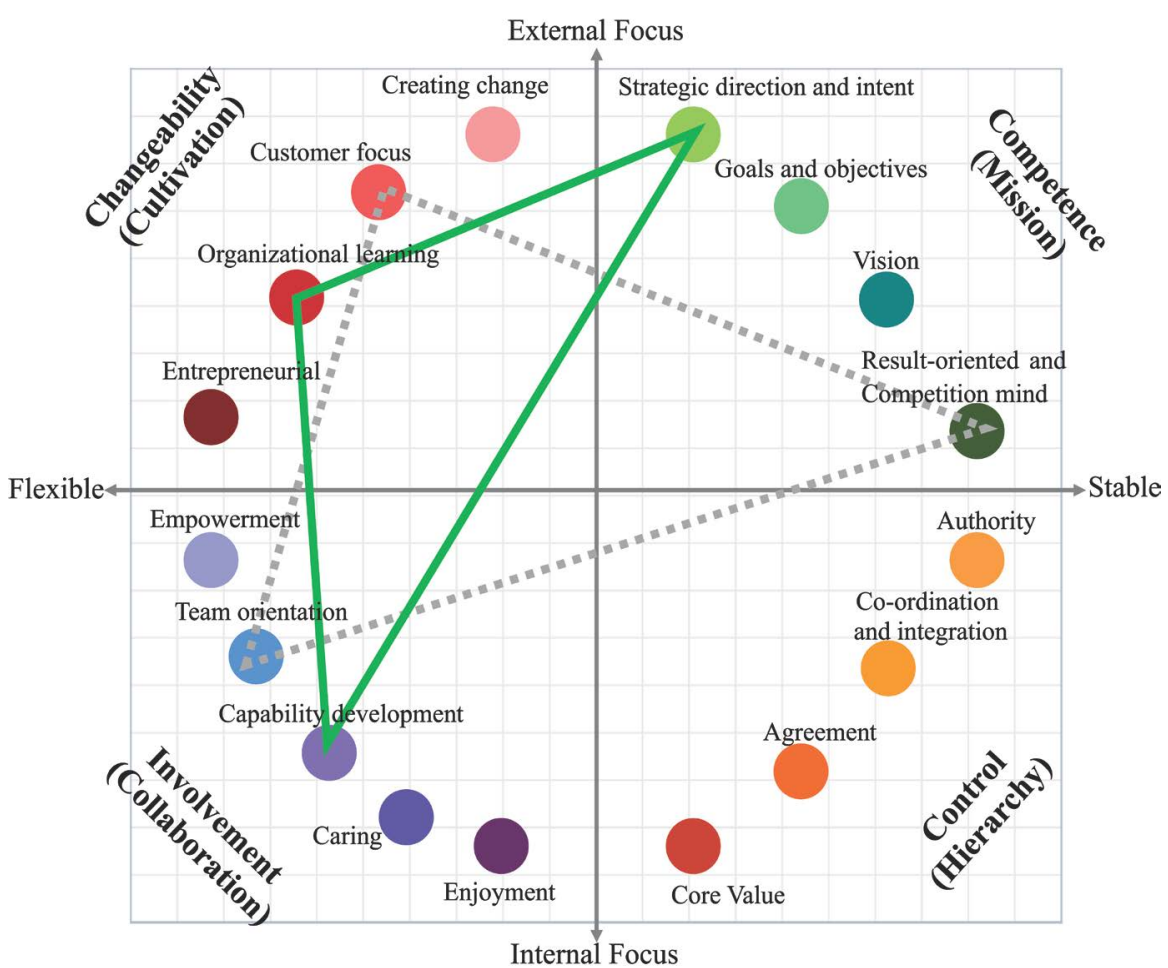

Figure 2. SLRI's cultures, cultural characteristics, and strengths.

executives and managers must practice this culture with care, i.e. not excessive, otherwise a backfire from staff members is predicted.

The cultural characteristics or styles must not be overemphasized because instead of being advantages they would become drawbacks. For example, an overemphasis on learning may lead to loosing of strategic intent and results-oriented mind; too much emphasis on results may lead to breakdown of communication and collaboration as well as high stress and anxiety. Readers may explore more on the issues in the essay [8].

The results of our quantitative and qualitative researches support our findings that SLRI's dominant cultures are competence, collaboration, and cultivation, which are characterized by the top 3 strengths namely strategic direction, capability development, and organizational learning. These dominant cultures solidly support our desire to be an excellent organization for services and innovations. Alike organizations could have similar cultures probably with different weights. As a government-owned enterprise, we must practice control culture to a lesser extent. Necessary activities are internal audit, risk management, internal control, and health-safety practice. Practicing the control culture does not introduce any contradiction to being excellent in service and innovation. Positively, the control culture helps ensure transparency, accountability, and safety of an enterprise. Some negative behaviors including self-centric orientation, and dodging of jobs are to be subdued. Managing the 3 dominant cultures at large is a complex task for company's leader. They naturally are paradoxical. For non-profit organization, safety and control culture still has its inevitable roles. Therefore, an effec- 
tive management to balance paradox and conundrum is a real challenge for company's leader.

Improvement of organizational performance can be achieved through effective culture change. The first and important step for leaders is to know the existing and dominant culture(s) of their organizations. If they want a culture change, they'll have to set a target culture, and master a leadership alignment, communication, organizational design, and articulate their desire [8]. Management through culture is becoming a powerful source of enterprise's sustainable competitive advantage.

Future researches may include assessing our sub-cultures, employee engagement, and work commitment.

\section{Conclusion}

The article has discussed a study to find-out existing and current cultures of an advanced physics institute, i.e. Synchrotron Light Research Institute (SLRI), Thailand. SLRI is a public organization (non-profit) owned by the Government of Thailand. It provides synchrotron radiation, scientific research, and engineering services to academia and industry. The authors applied quantitative and qualitative research approaches to explore a broad view of our existing cultures. As a result, SLRI's dominant cultures are competence, collaboration, and cultivation. These cultures are characterized by the top 3 strengths as follows: strategic direction, capability development, and organizational learning. The second-to-top strengths are team orientation, customer focus, and competitive mind. These support the same dominant cultures. Enhancing a little bit more on the second-to-top strengths will result in even greater organization performance. Additionally, cultures to be subdued are self-centric behavior, and dodging of jobs. Due to our governmental status, control culture must be practiced although to a lesser extent to ensure our transparency, accountability, and safety.

\section{Acknowledgements}

The authors thank their colleagues for an active participation of the study.

\section{Conflicts of Interest}

The authors declare no conflicts of interest regarding the publication of this paper.

\section{References}

[1] Trevor, J. (2019) Align: A Leaderships Blueprint for Aligning Enterprise Purpose, Strategy and Organisation. Bloomsbury Publishing, UK.

[2] Deal, T.E. and Kennedy, A.A. (1982) Corporate Culture: The Rites and Rituals of Corporate Life. Addison-Wesley, Reading, Mass.

[3] Johnson, G., Whittington, R., Scholes, K., Angwin, D. and RegnZr, P. (2013) Exploring Strategy. Pearson Education, UK. 
[4] Chartered Institute of Internal Auditors (2014) Culture and the Role of Internal Audit-Looking below the Surface. Chartered Institute of Internal Auditors, UK.

[5] Denison, D.R. (1990) Corporate Culture and Organizational Effectiveness. John Wiley \& Sons, New York.

[6] Schneider, W.E. (1994) The Reengineering Alternative: A Plan for Making Your Current Culture Work. Irwin Professional Publishing, New York.

[7] Cameron, K.S. and Quinn, R.E. (2011) Diagnosing and Changing Organizational Culture Based on the Competing Values Framework. 3rd Edition, Jossey-Bass, San Francisco.

[8] Groysberg, B., Lee, J., Price, J. and Cheng, J.Y. (2018) The Leader's Guide to Corporate Culture. Harvard Business Review, Brighton, 44-52.

[9] Ulrich, D. (2015) The Leadership Capital Index: Realizing the Market Value of Leadership. Berrett-Koehler Publishers, Oakland. 